\title{
Analysis of Soil Arching in Pipeline Installation Subjected to Uplift
}

\author{
Yuri D. Costa, Lucas S. Moraes, Carina L. Costa \\ Federal University of Rio Grande do Norte \\ Av. Sen. Salgado Filho, 3000, Natal - RN, Brazil \\ ydjcosta@ct.ufrn.br; lucas2006moraes@gmail.com; carina@ct.ufrn.br
}

\begin{abstract}
The vast extension of a buried pipeline can lead to many specific situations involving longitudinal interactions with the surrounding soil, such as landslides, expansive soils, sinkholes, collapsible soils, just to name a few. In this study, three-dimensional numerical simulations were carried out to evaluate the mechanical behavior of a buried pipe undergoing a localized elevation. Parametric analyses were performed considering soil relative density, pipe-soil relative stiffness and vertical surcharge loading. The results of the parametric study are relevant to the design of buried pipes under the action of uplift forces.
\end{abstract}

Keywords: pipe, arching, soil stress, envelope, elevation

\section{Introduction}

As an important infrastructure component of any city, buried pipes are used for water, sewer, telephone and electricity facilities. Pipelines are also used to transport products such as oil and gas. The design of buried pipelines requires a broad knowledge not only of the mechanical properties of the pipe itself, but also of aspects concerning the interaction with the surrounding soil, in order to properly resist thrusts and deformations.

Despite the progress achieved on the design of buried pipes during the last century, in many regions of the world, geotechnical aspects of the problem are still overlooked. In many situations, the geotechnical design of underground pipelines is limited to simply specifying the construction process [1].

This paper aims at presenting results of a numerical study on the mechanical behavior of a buried pipe undergoing elevation, which can be triggered by expansive soils, uplift water pressure, soil freezing, for instance. Emphasis is placed on the effect of soil arching within the pipeline soil envelope.

\section{Materials and Methods}

\subsection{Envelope Modelling}

Three-dimensional numerical analyses were performed using the Finite Element Method (FEM). The study was developed using the Plaxis 3D code. The problem analysed in this paper consisted of a pipeline with $305 \mathrm{~mm}$ in diameter (D) and $30 \mathrm{~m}$ in length, installed in a trench with $600 \mathrm{~mm}$ in width (B) and $1300 \mathrm{~mm}$ in depth.

The pipe upward movement was simulated by prescribed vertical displacements imposed to the soil beneath the central region of the pipe. A maximum prescribed displacement of $50 \mathrm{~mm}$ was considered for all analyses. Figure 1 illustrates the problem under evaluation. The extension of the region under elevation along the pipe was $15 \mathrm{~m}$.

The pipeline was simulated as a shell structure partitioned into slices of $1 \mathrm{~m}$ in length. The soil was modelled using the strain hardening constitutive model, and the pipe was modelled using the linear elastic model.

\subsection{Investigated Variables}

Parametric analyses were performed varying the relative density $\left(\mathrm{D}_{\mathrm{r}}\right)$ of the trench backfill soil, the relative stiffness (SR) of the soil-pipe system and surficial distributed surcharge loading (q). The values selected for these parameters were $\mathrm{D}_{\mathrm{r}}=25 \%, 50 \%, 75 \%$ and $100 \%, \mathrm{SR}=2000,4000,10000$ and 20000 and $\mathrm{q}=100,200,300$ and $400 \mathrm{kPa}$. 


\subsection{Parameters for the Materials}

The soil surrounding the trench is labelled SOIL 1 and the backfill soil is labelled SOIL 2 (Figure 1). Both soils are non-cohesive $(\mathrm{c}=0 \mathrm{kPa})$. The parameters used to represent Soil 1 are listed in Table 1.

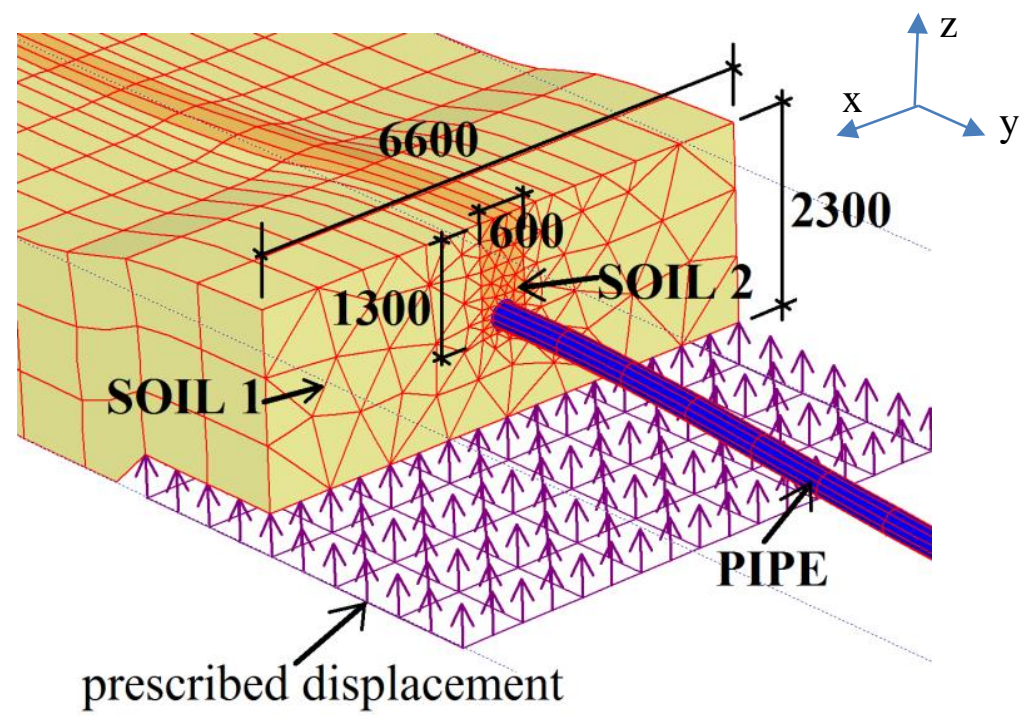

Fig. 1: Three-dimensional modelling of the problem. (Dimensions in $\mathrm{mm}$ ).

Carbon steel was chosen as the material for the pipe. According to the American Petroleum Institute (API), steels for pipelines in the oil industry are usually classified according to their application, chemical composition and mechanical strength. The pipe modelled in this work was the API 5L X70, which is commonly used in the pipeline industry. The parameters used for the pipe are shown in Table 2.

Further information about the numerical modelling can be found in [2].

Table 1: Parameters for Soil 1.

\begin{tabular}{|l|c|c|}
\hline \multicolumn{1}{|c|}{ Parameter } & Unit. & Value \\
\hline Relative Density $\left(\mathrm{D}_{\mathrm{r}}\right)$ & $\%$ & 100 \\
\hline Soil unit weight $(\gamma)$ & $\mathrm{kN} / \mathrm{m}^{3}$ & 17.70 \\
\hline Triaxial loading Stiffness $\left(\mathrm{E}_{50}\right)$ & $\mathrm{kN} / \mathrm{m}^{2}$ & 69360 \\
\hline Oedometer loading Stiffness $\left(\mathrm{E}_{\mathrm{oed}}\right)$ & $\mathrm{kN} / \mathrm{m}^{2}$ & 106757 \\
\hline Triaxial unloading Stiffness $\left(\mathrm{E}_{\mathrm{ur}}\right)$ & $\mathrm{kN} / \mathrm{m}^{2}$ & 208079 \\
\hline Cohesion $(\mathrm{c})$ & $\mathrm{kN} / \mathrm{m}^{2}$ & 0 \\
\hline Friction angle $(\phi)$ & ${ }^{2}$ & 39.20 \\
\hline Dilatancy angle $(\Psi)$ & $\circ$ & 13.40 \\
\hline Poisson's ratio $(v)$ & - & 0,41 \\
\hline
\end{tabular}

Table 2: Parameters for the pipe.

\begin{tabular}{|c|c|c|}
\hline Parameter & Unit. & Value \\
\hline Diameter (D) & $\mathrm{mm}$ & 305 \\
\hline Axial Stiffness (EA) & $\mathrm{kN} / \mathrm{m}$ & 1220531 \\
\hline Flexural Stiffness (EI) & $\mathrm{kNm} / \mathrm{m}$ & 4.10 \\
\hline Linear Weight $(\mathrm{w})$ & $\mathrm{kN} / \mathrm{m} / \mathrm{m}$ & 0.46 \\
\hline Thickness $(\mathrm{t})$ & $\mathrm{mm}$ & 3 to 8 \\
\hline Unit Weight $(\gamma)$ & $\mathrm{kN} / \mathrm{m}^{3}$ & 77.08 \\
\hline
\end{tabular}

\section{Results and Discussion}


The influence of the backfill relative density $\left(D_{r}\right)$ was evaluated for a 5-m long fixed elevation zone beneath the pipe. The purpose of this analysis was to investigate the benefits of a good backfill compaction on the overall behavior of a pipeline undergoing elevation.

Figure 2a shows the variation of the effective stresses in the soil mass $\left(\sigma_{\mathrm{v}}\right)$ with depth in the soil at pipe crown and invert. The effective stress is normalized by the initial geostatic stress $\left(\sigma_{\mathrm{vi}}\right)$ and the cover depth $(\mathrm{H})$ is normalized by the pipe diameter (D). The stresses were obtained at the central section of the model ( $\mathrm{z}=15 \mathrm{~m}$ from the edge of the pipe).

a)

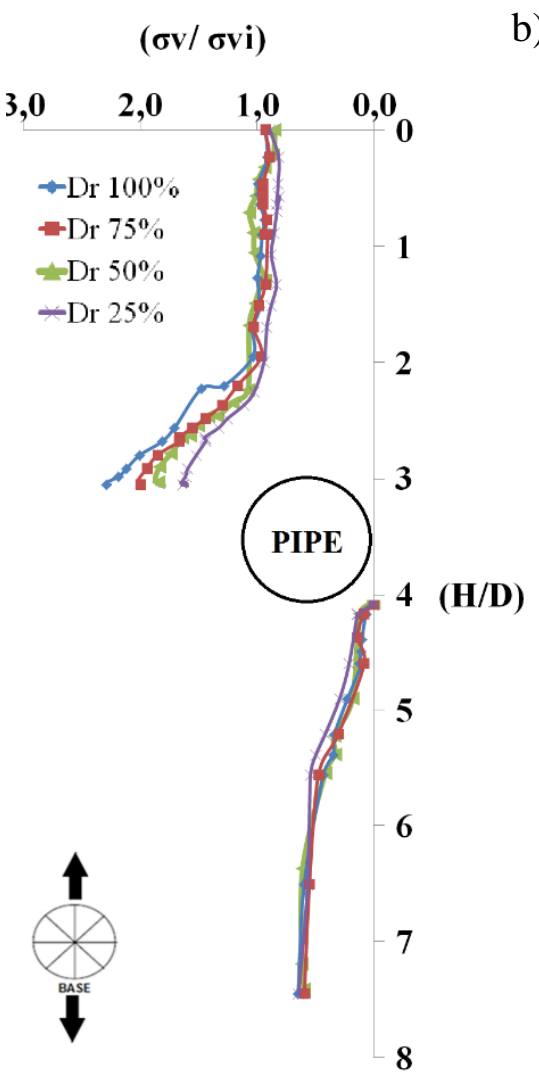

b)

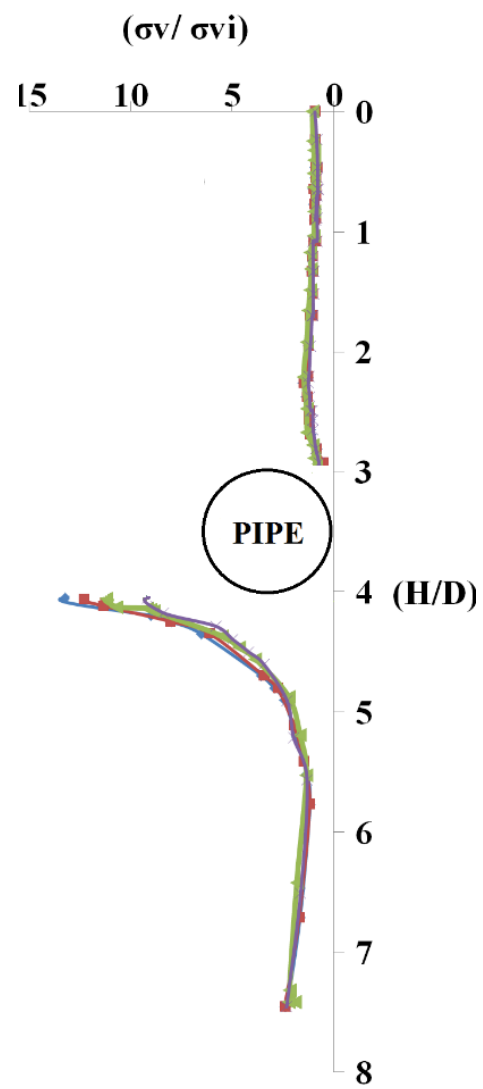

Fig. 2: Variation of stresses in the soil mass above and below the pipe for different values of relative density $\left(\mathrm{D}_{\mathrm{r}}\right)$. a) Model central section, and b) Model interface section.

Passive arching takes place at pipe crown, that is, stresses increase at that position. On the other hand, active arching occurs at pipe invert, which means reduction of stresses at that position. The measured stresses increased considerably above the pipe crown, whereas a significant relief took place at pipe invert. Stress increase at pipe crown is more evident for larger relative densities. In other words, arching develops more for well compacted backfills than for loose backfills, during elevation. Redistribution of stresses is concentrated within a vertical distance of about one pipe diameter above pipe crown. Above that depth, the ratio $\sigma_{\mathrm{v}} / \sigma_{\mathrm{vi}}$ remains close to unity. Similarly, stress redistribution below pipe base is more pronounced until a depth of $1.5 \mathrm{D}$.

The section at the interface between the zone of elevation and the stable soil mass was also evaluated and the results are shown in Figure $2 \mathrm{~b}$. This section is located at $\mathrm{z}=12.5 \mathrm{~m}$. An opposite trend is observed for this section, as compared to the central section. The stresses below the pipe increase considerably and are about five times larger than those at the central section. The stress distribution with depth is rather similar for the range of $\mathrm{D}_{\mathrm{r}}$ values used in this analysis. The stresses remained virtually constant above the pipe crown, for all values of $\mathrm{D}_{\mathrm{r}}$. No arching action was observed, since $\sigma_{\mathrm{v}} / \sigma_{\mathrm{vi}}$ is close to unity.

A comparison between Figures $2 \mathrm{a}$ and $2 \mathrm{~b}$ leads to the assumption that the interface section requires more attention in circumstances involving localized elevation of a buried pipeline. 
The relative stiffness (SR) is defined as the ratio between the soil stiffness $\left(\mathrm{S}_{\mathrm{S}}\right)$ and the pipe stiffness $\left(\mathrm{S}_{\mathrm{P}}\right)$, as shown by Equation 1 [3]:

$$
\mathrm{SR}=\frac{\mathrm{S}_{\mathrm{S}}}{\mathrm{S}_{\mathrm{P}}}
$$

The soil stiffness Ss is given by the following equation:

$$
S_{S}=\frac{E_{S}}{\left(1-v^{2}\right)}
$$

where Es is the soil Young's modulus and $v_{\mathrm{s}}$ is the soil Poisson ratio. $\mathrm{S}_{\mathrm{P}}$ is expressed by:

$$
S_{P}=\frac{E_{p} \cdot t^{3}}{12 D}
$$

where $E_{P}$ is the Young's modulus of the pipe material, $D$ is the pipe diameter and $t$ is the pipe wall thickness.

Pipe stiffness is a function of the ratio between the diameter and wall thickness (D/t). For a constant D of $305 \mathrm{~mm}$, the thickness of the pipe wall was varied from 3 to $8 \mathrm{~mm}$ in order to achieve different pipe stiffness values.

The results are presented in Figure 3, which shows the variation of the stress ratio $(\sigma \mathrm{v} / \sigma \mathrm{vi})$ at the pipe crown along pipe length. SR was varied from 1,000 to 20,000. Lower values for SR represent rigid systems and higher values of SR represent flexible systems.

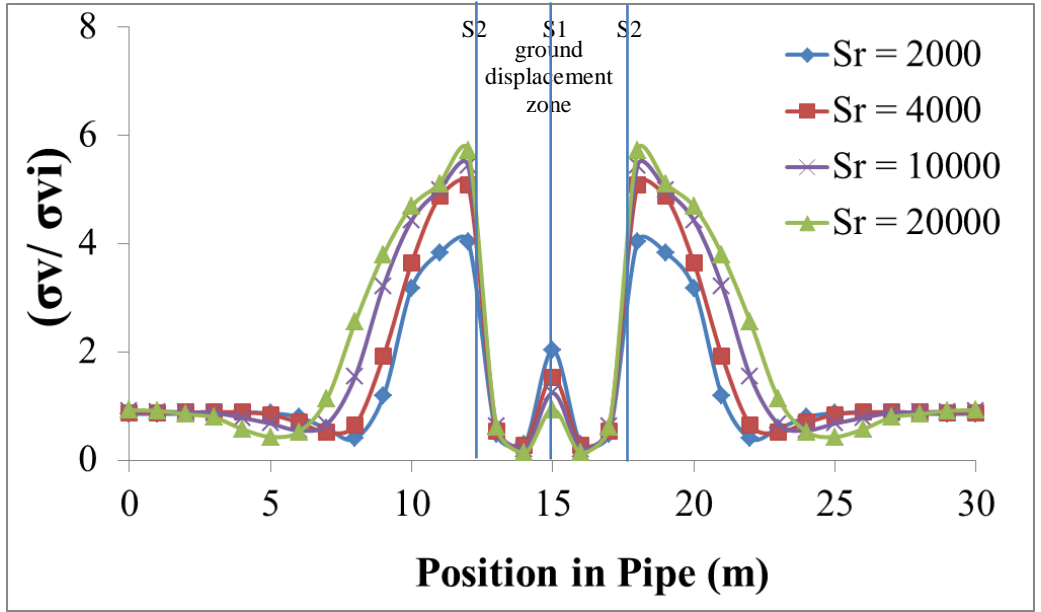

Fig. 3: Variation of stresses at the pipe crown for different values of relative stiffness $\left(S_{R}\right)$.

The data shown in Figure 3 reveals large stress peaks at positions corresponding to the interface sections and a lower stress peak at the central section of the pipe.

The stresses at the top of the pipe appeared to be very sensitive to changes in relative stiffness around the interface sections (S2) and less sensitive around the central section (S1). Moreover, stresses are higher at the central section for more rigid systems. A reversed situation occurs at the interface section, which experiences larger stresses with more flexible systems.

In order to check the influence of surcharge loading on the behaviour of buried pipe undergoing elevation, a distributed vertical patch load was applied on the surface of the model over the central section of the pipe. Stresses $q=100$, 200,300 and $400 \mathrm{kPa}$ were chosen for this analysis. Simultaneously, an upward vertical displacement of $50 \mathrm{~mm}$ was imposed to the soil mass under the pipe, over a length of $5 \mathrm{~m}$ along pipe longitudinal axis. Figure 4 shows the variation of 
the vertical stresses developed at the pipe invert along pipe longitudinal axis. The vertical stresses are normalized by the initial vertical geostatic stresses.

As noted, the results showed a stress peak on a region along the pipeline between sections S1 and S2. The increase in surcharge load caused a reduction in stresses at the invert. Thus, in this situation the surficial surcharge loading attenuated the arching phenomenon triggered by the located elevation.

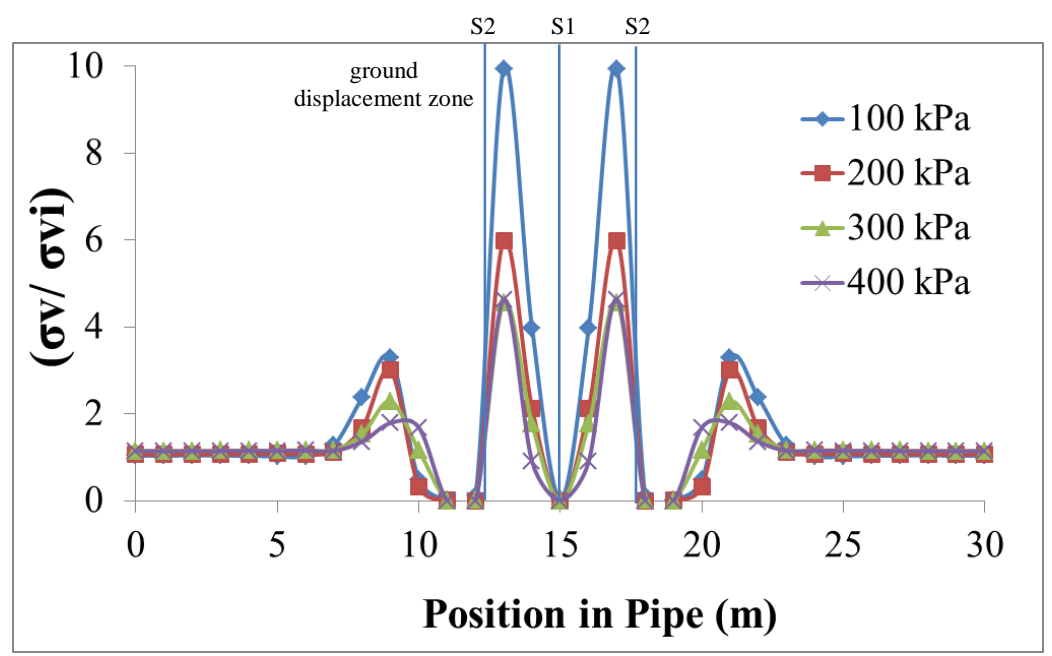

Fig. 4: Variation of the vertical stresses along the pipe invert for different values of surcharge loads.

\section{Conclusion}

A parametric study has been undertaken to evaluate the behavior of buried pipes undergoing a localized elevation. From the results of the numerical analysis, it has been found that looser backfills can slightly reduce the stresses above pipe crown at the central region of the pipe subjected to uplift.

Soil-pipe systems with higher relative stiffness showed to be less susceptible to stress variations in the central region of ground movement, whereas an opposite trend was observed for the regions beyond ground movement.

It was also noted that surcharge vertical loads applied to the surface reduce the stresses triggered by the elevation of the pipe.

\section{Acknowledgements}

The authors would like to express their gratitude for the financial support provided to this research by the Brazilian Research Agency CNPq.

\section{References}

[1] B. S. Bueno, Y. D. Costa. Buried pipes - geotechnical aspects. 2nd ed, São Paulo: Oficina de Textos, pp. 240,2012 [in portuguese].

[2] L. S. Moraes, "Numerical Analysis of Buried Pipes undergoing a Localized Elevation and Settlement," M.S. thesis, Federal University of Rio Grande do Norte, Brazil, 2014. [in Portuguese].

[3] J. E. Gumbel, M. P. O'Reilly, L. M. Lake, D. R. Carder, "The development of a new design method for buried flexible pipes," in Europipe'82 Proceedings Basel, pp. 87-98, 1982. 